


\title{
Shear Bond Strength of a Chemical Resin Cement to Five Adhesive Systems in Bovine Dentin
}

\author{
Claudio Hideki Kubo, Taciana Marco Ferraz Caneppele, Eduardo Galera da Silva, Maria Filomena Rocha Lima Huhtala, \\ Carlos Rocha Gomes Torres, Clóvis Pagani, Ana Paula Martins Gomes
}

\section{ABSTRACT}

Aim: This in vitro study evaluated the shear bond strength of a chemical resin cement to five adhesive systems in bovine dentin.

Materials and methods: One hundred and three bovine teeth were divided into five experimental groups $(n=19)$ and two control groups $(n=4)$. A flat dentin surface was exposed on each tooth after wet grinding the buccal enamel, in order to apply the adhesive systems (Adper Single Bond, Adper Scotchbond Multi-Purpose, Multi Bond Uno plus Duo, One Step, Prompt L-Pop) to 95 teeth, according to manufacture's instructions. Four teeth were etched with phosphoric acid (negative control) and four teeth were no etched with phosphoric acid (positive control). Light-cured composite blocks were sandblasted before the cementation with C\&B Cement (Bisco) over the treated dentin. The specimens were stored in distilled water at $37^{\circ} \mathrm{C}$ and submitted to the shear bond strength test after 7 days.

Results: ANOVA and Tukey tests $(p=0.05)$ demonstrated that Adper Single Bond (7.47 \pm 4.37$)$, Adper Scotchbond MultiPurpose $(6.68 \pm 5.11)$ and One Step $(7.30 \pm 4.29)$ presented the highest bond strength values. Prompt L-Pop $(0.05 \pm 0.17)$ and Multi Bond Uno plus Duo $(0.72 \pm 1.41)$ presented the lowest significant bond strength values.

Conclusion: The shear bond strength of composite resin cylinders cemented with chemically activated resin cement depends on the adhesive system used.

Clinical significance: Fourth and fifth generation light polymerized bonding systems are indicated when selfpolymerizing cements are used.

Keywords: Laboratory research, Material testing, Dentin adhesives, Shear bond strength.

How to cite this article: Kubo $\mathrm{CH}$, Caneppele TMF, da Silva EG, Huhtala MFRL, Torres CRG, Pagani C, Gomes APM. Shear Bond Strength of a Chemical Resin Cement to Five Adhesive Systems in Bovine Dentin. World J Dent 2012;3(2):150-155.

Source of support: Nil

Conflict of interest: None declared

\section{INTRODUCTION}

The use of adhesive restorative materials has brought about a revolution in restorative procedures. In the early 1990s, the concept of selective enamel etching was replaced by total-etching of enamel and dentin. For this purpose, in fourth generation adhesive systems (three-step) or fifth generation (two-step) systems, the smear layer is removed by using acids and subsequently applying a solution of hydrophilic monomers dissolved in water, alcohol and/or acetone (primers) to the dentin, which increases the surface energy and facilitates penetration of the resin fluid, with or without load, forming an interdiffusion zone between the resin and dentin, the hybrid layer. ${ }^{1}$

Recently, the numbers of steps and adhesive system application times have been reduced, consequently allowing a reduction in the number of errors in the application technique. These adhesive systems contain acid monomers that simultaneously etch and prepare the enamel and dentin (self-etch primer) without requiring complete smear layer removal. These adhesive systems involve two-step application (application of the self-etching primer and the adhesive, sixth generation adhesive systems) or single step (one-step self-etching, all-in-one, seventh generation adhesive systems). ${ }^{1,2}$ After application of the adhesive system to the dental substrate, the material is chemically polymerized (self-polymerized) by using light (light polymerization) or dual cure: Chemical and light polymerization, allowing direct or indirect tooth restoration to be performed.

Light-polymerized resin composites have largely superseded the use of chemically polymerized composites in esthetic dental applications. They offer distinct advantages, such as improved storage stability, extended working time, increased degree of conversion, reduced air porosities caused by mixing and enhanced physical properties. However, in areas that are not easily penetrable by light, chemically polymerized resin composites are frequently used as core build-up materials or as luting agents for endodontic posts, crowns and bridges, inlays and onlays, and allows the dentist to better identify the demarcation line of the core build-up, especially when it is located subgingivally, because it is more opaque. ${ }^{3}$ Sanares et $\mathrm{al}^{4}$ verified lower bond strength values in chemically polymerized resin composite specimens in comparison with light-polymerized specimens, when fifth generation adhesive systems (Prime and Bond, OptiBond SOLO, Single Bond, One Step) were used. Tay et $\mathrm{al}^{5,6}$ found that there were incompatibilities between the chemically activated or dual polymerization (light and chemical) adhesive systems and resin composites. 
Therefore, the aim of this study was to evaluate in vitro the shear bond strength between bovine dentin, five adhesive systems, self-polymerized resin cement and one indirect restorative material. The null hypothesis tested was that the shear bond strength of composite resin cylinders cemented with self-polymerized resin cement does not depend on the adhesive system used.

\section{MATERIALS AND METHODS}

\section{Dentin Surface Preparation}

This study was approved by the Research Ethics Committee of the São José dos Campos Dental School, UNESP, São Paulo, Brazil (022/2006-PA/CEP). One hundred and three bovine teeth from approximately 3-year-old animals were used. The teeth were cleaned with manual instruments, immersed in distilled water and frozen at $-18^{\circ} \mathrm{C}$ until used, which did not exceed a period of 28 days. ${ }^{7-9}$ Bovine teeth were chosen because they are easy to obtain, allow standardization regarding the dental substrate age and do not require disinfection or sterilization agents and storage mediums that may influence the bond strength results. ${ }^{9}$

The crowns were separated from the roots with a carborundum disk $1 \mathrm{~mm}$ below the cement-enamel junction. Pulp tissues were removed from the teeth through the cervical orifices with the aid of a Hedströem file number 80 (Dentsply, Tulsa, Oklahoma, USA). On the lingual face of teeth, pulp chamber opening was done with a spherical diamond tip (\#1014, KG Sorensen, São Paulo, São Paulo, Brazil) and thickness was standardized with a thickness meter (Bio-Art, Ribeirão Preto, São Paulo, Brazil) at $2 \mathrm{~mm}$ $\pm 0.1 \mathrm{~mm} .{ }^{10}$ After drying the apical and lingual openings were sealed with utility wax (Epoxiglass, Diadema, SP, Brazil) to prevent the penetrating of the acrylic resin (Clássico Produtos Odontológicos, Rio de Janeiro, RJ, Brazil) into the teeth during embedding.

Flat superficial dentin surfaces were created by removing the buccal enamel by wet grinding the buccal surfaces parallel to long axis of the teeth on a polishing machine with 300 grit SiC paper (Buehler Ecomet V, Buehler Ltd, Lake Bluff, IL, USA). To create a smear layer as standardized as possible, the dentine surfaces were finished for 1 minute by wet grinding with grit $600 \mathrm{SiC}$ paper, and were then randomly assigned to one of five adhesive systems. ${ }^{11}$

A Mylar strip (3M, Campinas, São Paulo, Brazil) with a $3 \mathrm{~mm}$ hole was used as a spacer and template. It was placed on the flat buccal dentin to obtain a controlled surface area for bonding with a uniform adhesive thickness. ${ }^{11}$ The bonding agents used in this study, and their compositions are listed in Table 1. Adper Scotchbond Multi-Purpose (3M/
ESPETM, St. Paul, Mn, USA), Adper Single Bond (3M/ ESPETM, St. Paul, Mn, USA), Prompt L-Pop (3M/ESPETM, St. Paul, Mn, USA) and One Step (Bisco Inc., Schaumburg, IL, USA) were selected because they are available in light polymerized formulations. Multi Bond Uno plus Duo (DFL, Rio de Janeiro, RJ, Brazil) was selected because when mixed it is available in self-polymerizing formulations. Table 2 shows the successive steps in each of the bonding procedures for bonding to dentin and luting agent, as prescribed by the manufacturer, and as they were used in the experiments. In control groups, four teeth each were treated with $37 \%$ phosphoric acid (Dentsply, Petrópolis, Rio de Janeiro, RJ, Brazil) or not, and no bonding system was applied.

\section{Preparation of Composite Blocks to Bond to Dentin}

Resilab Master composite (Wilcos do Brasil Ltd., Petrópolis, Rio de Janeiro, RJ, Brazil, Batch number: 089/04), shade A2 was placed in a teflon mold (height $\times$ diameter $=3 \times 3$ $\mathrm{mm}$ ) and light polymerized with XL-3000 (3M ESPE, St Paul, MN, USA, $450 \mathrm{~mW} / \mathrm{cm}^{2}$ ) on each side for 40 seconds. After light polymerization the cylindrical composite block was removed and one of the flat surfaces (to be used as the bonding area) was sandblasted (Microetcher, 50 microm$\mathrm{Al}_{2} \mathrm{O}_{3}$ ), ultrasonically cleaned in distilled water for 3 minutes and dried.

\section{Bonding Procedure and Adhesive Evaluation}

The C\&B (Bisco Inc., Schaumburg, IL, USA) was selected because it can be subjected to self-polymerization. A modified parallelometer (Bio Art Equipamentos Odontológicos Ltda., São Carlos, SP, Brazil) was used to standardize the cementation procedure. A fixed horizontal arm was adapted to the parallelometer, the spring of the vertical movable portion was removed, and a flat tip was coupled to the vertical arm to maintain the disk to be cemented in position. ${ }^{12}$ The weight of the vertical arm produced a constant static load of $300 \mathrm{gm}$ applied for 5 minutes to standardize resin cement thickness, and cement excess was removed with a brush. The specimens were stored in distilled water at $37^{\circ} \mathrm{C}$ for 7 days. After the storage period, each specimen was tested, by being attached to a shear bond strength testing device and placed in a universal testing machine (Model DL 2000/1000; EMIC, São José dos Pinhais, Paraná, Brazil). Shear bond testing was conducted at a crosshead speed of $0.5 \mathrm{~mm} / \mathrm{min}$ until failure occurred. The shear bond strength was determined by dividing the load at failure by the cross-sectional area of the bonded samples. 


\section{Statistical Analysis}

Shear bond strength value was recorded in MPa and analyzed using Statistix statistical software package 8.0 (Analytical software, USA). One-way ANOVA and Tukey's test were used to identify statistical differences between pairs of means. Statistical significance was set at $\alpha=0.05$ for all tests.

\section{RESULTS}

Table 3 shows the means and standard deviation of shear bond strength produced by the different experimental groups. ANOVA showed that significant differences were observed for the experimental groups $(\mathrm{p}<0.05)$. Groups 1 , 2 and 3 significantly presented the highest bond strengths. The lowest bond strengths were found in groups 4 and 5 .

\section{DISCUSSION}

There are numerous methods available for evaluating the adhesion of dental materials to teeth. In vitro measurement of bond strength is the commonest method of evaluating the presence and extent or value of the adhesive bond. The shear bond strength test involves loading the adhesive surface in shear until fracture occurs. The advantage of this test method is that it is relatively simple with respect to specimen preparation, equipment required and test setup. ${ }^{11,13}$ In this study, shear bond strength test was used to screen for potentially large differences among the combinations of bonding agent and resin cement and thus the null hypotheses tested in this study had to be rejected.

Although there is a lack of literature on the bond strength of adhesives used with resin luting cements, numerous studies have measured the bond strengths of bonding agents in combination with resin composite restorative materials. ${ }^{2,11,13,14}$ Adper Scotchbond Multi-Purpose (Group 1) was used as a control material in which the primer and adhesive are provided separately. Adper Single Bond (Group 2) and One Step (Group 3) were formulated with the primer and adhesive combined in one bottle. Light polymerized 1-bottle and 2-bottle variants from a single manufacturer yielded similar bond strength (Table 3 ), which suggests that the bond strength between the bonding agent

Table 1: Bonding systems used

\begin{tabular}{|c|c|c|}
\hline Bonding systems/type & Number of steps & Composition \\
\hline $\begin{array}{l}\text { Adper Scotchbond } \\
\text { Multi-Purpose } \\
\text { 3M-ESPE }\end{array}$ & Three-step total-etch adhesive & $\begin{array}{l}\text { Primer-aqueous solution of 2-hydroxyethyl methacrylate } \\
\text { (HEMA) and a copolymer of polyalkenoic acid (batch } \\
\text { number: } 2 Y U \text { ) } \\
\text { Bonding-solution of Bis-GMA, HEMA and } \\
\text { camphoroquinone (batch number: } 2 \mathrm{MR} \text { ) }\end{array}$ \\
\hline $\begin{array}{l}\text { Adper Single Bond } \\
\text { 3M-ESPE }\end{array}$ & $\begin{array}{l}\text { Two-step total-etch } \\
\text { adhesive }\end{array}$ & $\begin{array}{l}\text { Primer/bonding_-bisphenol A diglycidyl methacrylate } \\
\text { (Bis-GMA), polyalkenoic acid copolymer, dimethacrylates, } \\
\text { 2-hydroxyethyl methacrylate (HEMA), photoinitiators, } \\
\text { ethanol and water }\end{array}$ \\
\hline $\begin{array}{l}\text { One Step } \\
\text { Bisco Inc }\end{array}$ & Two-step total-etch adhesive & $\begin{array}{l}\text { Primer/bonding-biphenyl } \\
\text { dimethacrylate (BDPM), bisphenol A diglycidyl methacrylate } \\
\text { (Bis-GMA), 2-hydroxyethyl methacrylate (HEMA), amine, } \\
\text { photoinitiators and acetone }\end{array}$ \\
\hline $\begin{array}{l}\text { Multi Bond Uno } \\
\text { plus Duo } \\
\text { DFL }\end{array}$ & $\begin{array}{l}\text { Two-step total-etch } \\
\text { adhesive com dual } \\
\text { cure activator }\end{array}$ & $\begin{array}{l}\text { Primer/bonding Universal (Uno)- } \\
\text { PMGDM (glycerin-dimethacrylate and } \\
\text { pyromellitic dianhydride in acetone), HEMA } \\
\text { (hydroxyethyl methacrylate), PHFA (potassium } \\
\text { hexafluoroantimonate), camphoroquinone, 4-EDAMB } \\
\text { (ethyl-4-dimethylaminobenzoate) and butyl hydroxy toluene } \\
\text { (batch number: 06010074) } \\
\text { Primer/bonding catalyst (Duo)—Sodium NTG-GMA } \\
\text { [N-(2-hydroxy-3-(2-methyl1-oxo-2-propeny)oxy) propyl]- } \\
\text { N-tolyl sodium glycine and acetone (batch number: } \\
06010112 \text { ) }\end{array}$ \\
\hline $\begin{array}{l}\text { Prompt L-Pop } \\
\text { 3M-ESPE }\end{array}$ & One-step self-etch & $\begin{array}{l}\text { Bonding (A) etchant/primer-mono and } \\
\text { di-hema phosphates, dimethacrylate, camphoroquinone, } \\
\text { replaced aromatic amine and replaced phenol } \\
\text { Bonding (B) water, hydroxymethyl methacrylate }\end{array}$ \\
\hline $\begin{array}{l}\text { C \& B } \\
\text { Bisco Inc }\end{array}$ & Cement self-cured & $\begin{array}{l}\text { Base_bisphenol A diglycidyl methacrylate, } \\
\text { ethoxylated bisphenol A dimethacrylate, } \\
\text { Silica, glass frit, sodium fluoride } \\
\text { Catalyst—silica, bisphenol A diglycidyl methacrylate, } \\
\text { triethylene glycol dimethacrylate }\end{array}$ \\
\hline
\end{tabular}


Table 2: Bonding procedures in accordance with the adhesive system manufacturers' instructions

\begin{tabular}{|c|c|c|}
\hline Groups & Adhesive & Dentin conditioning \\
\hline 1 & Adper Scotchbond Multi-Purpose & $\begin{array}{l}37 \% \text { phosphoric acid (15s), rinsed (15s), blotted with filter paper (wet } \\
\text { condition), primer applied (15s), air dried ( } 5 \mathrm{~s}) \text {, covered with adhesive (30s), } \\
\text { air thinned (3s), re-applied (30s), air dried (3s) and light cured (30s) }\end{array}$ \\
\hline 2 & Adper Single Bond & $\begin{array}{l}37 \% \text { phosphoric acid (15s), rinsed (15s), blotted with filter paper (wet } \\
\text { condition), adhesive (30s), air thinned (3s), reapplied (30s), air dried (3s) } \\
\text { and light cured (30s) }\end{array}$ \\
\hline 3 & One Step & $\begin{array}{l}\text { 32\% phosphoric acid (15s), rinsed (15s), blotted with filter paper (wet } \\
\text { condition), adhesive ( } 30 \mathrm{~s}) \text {, air thinned (3s), reapplied (30s), air dried (3s), } \\
\text { and light cured (10s) }\end{array}$ \\
\hline 4 & Multi Bond Uno plus Duo & $\begin{array}{l}37 \% \text { phosphoric acid (15s), rinsed (15s), blotted with filter paper (wet } \\
\text { condition), adhesive (two drops of Uno to one drop of Duo), applied (30s), } \\
\text { reapplied (30s) and air dried (3s), and light cured }\end{array}$ \\
\hline 5 & Prompt L-Pop & $\begin{array}{l}\text { One coat of adhesive applied and brushed (15s), waited for } 3 \text { minutes, lightly air } \\
\text { dried (15s), and light cured (10s), reapplied (15s), air dried (15s) and light } \\
\text { cured (10s) }\end{array}$ \\
\hline 6 & Negative control group & $\begin{array}{l}37 \% \text { phosphoric acid (15s), rinsed (15s), blotted with filter paper (wet } \\
\text { condition) }\end{array}$ \\
\hline 7 & Positive control group & Dentin surface rinsed (15s), blotted with filter paper \\
\hline
\end{tabular}

Table 3: Means and standard deviation of shear bond strength for the experimental and control groups

\begin{tabular}{llcc}
\hline Groups & Adhesive system & $n$ & Mean \pm standard deviation \\
\hline 1 & Adper Scotchbond Multi-Purpose & 19 & $6.68^{\mathrm{a} *} \pm 5.11$ \\
2 & Adper Single Bond & 19 & $7.47^{\mathrm{a}} \pm 4.37$ \\
3 & One Step & 19 & $7.30^{\mathrm{a}} \pm 4.29$ \\
4 & Multi Bond Uno plus Duo & 19 & $0.72^{\mathrm{b}} \pm 1.41$ \\
5 & Prompt L-Pop & 19 & $0.05^{\mathrm{b}} \pm 0.17$ \\
6 & Negative control group & 4 & $2.63^{\mathrm{c}} \pm 1.10$ \\
7 & Positive control group & 4 & $0.91^{\mathrm{b}} \pm 0.67$ \\
\hline
\end{tabular}

*Means accompanied by the same letters presented no statistically significant differences

and the resin cement cannot be attributed to the solvent (water or acetone, Table 1) or manner of delivering the bonding agent. Similar results were found by previous studies. ${ }^{13,15}$

Some combinations of bonding agent and resin cement yielded low bond strength (Table 3). The lowest bond strength values were recorded for the chemical or selfpolymerizing resin cement combined with the light polymerized Prompt L-Pop (Group 5). Recently, it has been shown that incompatibilities can occur when chemically polymerized composites are combined with adhesives containing acidic monomers. ${ }^{3-6,16,17}$ Bolhuis et $\mathrm{al}^{3}$ verified that the monomer used in the adhesive SE Bond is 10-methacryloyloxydecyl dihydrogen phosphate (MDP), which is an acidic monomer producing a $\mathrm{pH}$ of 1.8 in the adhesive liquid. This monomer will therefore also be present in the oxygen inhibition layer after the adhesive has been light polymerized. When the chemically polymerized composite is brought into contact with it, the tertiary amine in the composite, necessary for the activation of the benzoylperoxide initiator will be protonized and thereby be inactivated. This will affect the formation of starting radicals and thus the polymerization of the contact layer of the composite. ${ }^{18}$ Moreover, starting radicals that did form in the composite contact layer will be converted into inactive peroxyradicals until all the air oxygen in the inhibition layer is consumed. ${ }^{3}$ Tay and Pashley ${ }^{19}$ verified that acidic resin monomers in Prompt L-Pop consist of methacrylated phosphoric acid mono and diesters, in which pH (1.0) is low enough to completely dissolve smear layer. In group 5, the incompatibility of components of different manufacturer's materials and chemical formulations (residual acidic resin monomers from bonding agent interacted with binary peroxide-amine catalytic components present in self-polymerizing resin cement) probably contributed to bond strengths observed in this study.

Bolhuis et $\mathrm{al}^{3}$ also verified that dual-polymerized adhesives with acid monomers are more favorable for combining with chemically polymerized composites. The authors verified that the dual polymerization adhesive (Photo Bond, Kuraray) contains a salt (sodium benzene sulfinate) which help to polymerize the acid monomers, probably by preventing the protonization of the amine. Salz et $\mathrm{al}^{20}$ concluded that with a good adjustment of radical 
polymerization initiators (DEPT - N,N-di(2-hydroxyethyl) p-toluidine) used in self-polymerizing systems and acidic monomers incorporated in self-etching adhesives, high bond strengths can be achieved.

The adhesive Multi Bond Uno plus Duo (Group 4), in the Duo bottle presented sodium NTG-GMA (Table 2), which allowed it to be used as a light and chemically polymerized adhesive (dual polymerized) or only chemically polymerized adhesive. In this study, chemical polymerization of Multi Bond was opted for, and the lowest bond values were verified. Dong et al ${ }^{13}$ have speculated that the acidity of the Prime and Bond NT (dipentaery-thritol pentaacrylate phosphate Ester - PENTA molecule used) may affect the degree of conversion of the bonding agent or the self-polymerizable resin cement. Furthermore, when the cement RelyX ARC (3M Dental Products, St. Paul, MN, USA) was used with the adhesive Prime and Bond NT polymerized chemically, the lowest bond strength values were found. Incompatibility of components of different manufacturer's materials and/or chemical formulations of group 4 probably contributed to bond strengths observed in this study.

Groups 6 and 7 (2.63 MPa and 0.91 MPa) produced higher bond strength values than groups 4 and 5 . In these groups, no adhesive system was applied on the dentin surface so that the bond strength values of the cement on dentin with and without a smear layer could be verified. These results reinforced the hypotheses that there was incompatibility of the components of different materials (adhesive system/resinous cement) used in the present study, due to the differences in formulation, type of solvent, film thickness, degree of oxygen inhibition, proportion of hydrophilic to hydrophobic components and efficiency of the initiator system.

In future experiments with this set-up, the morphology of fractured surfaces will be studied by SEM to establish the factors in the adhesive layer in greater detail. Prudence in the combinations of bonding agents and resin cements is the first step in achieving predictable long-term clinical results.

\section{CONCLUSION}

The present study has shown that: (1) The bond strength of resin composite cylinders cemented with chemically activated resinous cement does depend on the adhesive system used; (2) Adper Single Bond, Adper Scotchbond Multi-Purpose and One Step presented the highest bond strength values; (3) Prompt L-Pop and Multi Bond Uno plus Duo presented the lowest bond strength values; (4) Fourth and fifth generation light polymerized bonding systems are indicated when self-polymerizing cement is used.

\section{REFERENCES}

1. El Zohairy AA, De GeeAJ, Mohsen MM, Feilzer AJ. Effect of conditioning time of self-etching primers on dentin bond strength of three adhesive resin cements. Dent Mater 2005;21:83-93.

2. Soderholm KJ, Guelmann M, Bimstein E. Shear bond strength of one 4th and two 7th generation bonding agents when used by operators with different bonding experience. J Adhes Dent 2005;7:57-64.

3. Bolhuis PB, de Gee AJ, Kleverlaan CJ, El Zohairy AA, Feilzer AJ. Contraction stress and bond strength to dentin for compatible and incompatible combinations of bonding systems and chemical and light-cured core build-up resin composites. Dent Mater 2006; 22:223-33.

4. Sanares AM, Itthagarun A, King NM, Tay FR, Pashley DH. Adverse surface interactions between one-bottle light-cured adhesives and chemical-cured composites. Dent Mater 2001; 17:542-56.

5. Tay FR, Pashley DH, Yiu CK, Sanares AM, Wei SH. Factors contributing to the incompatibility between simplified-step adhesives and chemically-cured or dual-cured composites. Part I. Single-step self-etching adhesive. J Adhes Dent 2003;5: 27-40.

6. Tay FR, Suh BI, Pashley DH, Prati C, Chuang SF, Li F. Factors contributing to the incompatibility between simplified-step adhesives and self-cured or dual-cured composites. Part II. Single-bottle, total-etch adhesive. J Adhes Dent 2003;5:91-105.

7. Patierno JM, Rueggeberg FA, Anderson RW, Weller RN, Pashley DH. Push-out strength and SEM evaluation of resin composite bonded to internal cervical dentin. Endod Dent Traumatol 1996;12:227-36.

8. Tonami K, Takahashi H, Nishimura F. Effect of frozen storage and boiling on tensile strength of bovine dentin. Dent Mater J 1996;15:205-11.

9. Titley KC, Chernecky R, Rossouw PE, Kulkarni GV. The effect of various storage methods and media on shear-bond strengths of dental composite resin to bovine dentine. Arch Oral Biol 1998; 43:305-11.

10. Nakamichi I, Iwaku M, Fusayama T. Bovine teeth as possible substitutes in the adhesion test. J Dent Res 1983;62:1076-81.

11. Teixeira EC, Bayne SC, Thompson JY, Ritter AV, Swift EJ. Shear bond strength of self-etching bonding systems in combination with various composites used for repairing aged composites. J Adhes Dent 2005;7:159-64.

12. Nagayassu MP, Shintome LK, Uemura ES, Araujo JE. Effect of surface treatment on the shear bond strength of a resin-based cement to porcelain. Braz Dent J 2006;17:290-95.

13. Dong CC, McComb D, Anderson JD, Tam LE. Effect of mode of polymerization of bonding agent on shear bond strength of autocured resin composite luting cements. J Can Dent Assoc 2003;69:229-34.

14. Sadek FT, Goracci C, Cardoso PE, Tay FR, Ferrari M. Microtensile bond strength of current dentin adhesives measured immediately and 24 hours after application. J AdhesDent 2005; 7:297-302.

15. Pfeifer C, Shih D, Braga RR. Compatibility of dental adhesives and dual-cure cements. Am J Dent 2003;16:235-38.

16. Tabak LA, Levine MJ, Mandel ID, Ellison SA. Role of salivary mucins in the protection of the oral cavity. J Oral Pathol 1982; 11:1-17. 
17. Silva e Souza MH, Jr., Carneiro KG, Lobato MF, Silva e Souza Pde A, de Goes MF. Adhesive systems: Important aspects related to their composition and clinical use. J Appl Oral Sci 2010; 18:207-14

18. Tay FR, Gwinnett JA, Wei SH. Micromorphological spectrum from overdrying to overwetting acid-conditioned dentin in waterfree acetone-based, single-bottle primer/adhesives. Dent Mater. 1996;12:236-44.

19. Tay FR, Pashley DH. Aggressiveness of contemporary selfetching systems. I: Depth of penetration beyond dentin smear layers. Dent Mater 2001;17:296-308.

20. Salz U, Zimmermann J, Salzer T. Self-curing, self-etching adhesive cement systems. J Adhes Dent 2005;7:7-17.

\section{ABOUT THE AUTHORS}

\section{Claudio Hideki Kubo}

Trainee at Clinical Group Research, Department of Restorative Dentistry, São José dos Campos Dental School, São Paulo State University, São Paulo, Brazil

\section{Taciana Marco Ferraz Caneppele}

Trainee at Clinical Group Research, Department of Restorative Dentistry, São José dos Campos Dental School, São Paulo State University, São Paulo, Brazil

\section{Eduardo Galera da Silva}

Assistant Professor, Department of Social Dentistry and Pediatric Clinical, São José dos Campos Dental School, São Paulo State University, São Paulo, Brazil

\section{Maria Filomena Rocha Lima Huhtala}

Assistant Professor, Department of Restorative Dentistry, São José dos Campos Dental School, São Paulo State University, São Paulo Brazil

\section{Carlos Rocha Gomes Torres}

Assistant Professor, Department of Restorative Dentistry, São José dos Campos Dental School, São Paulo State University, São Paulo Brazil

\section{Clóvis Pagani}

Associate Professor, Department of Restorative Dentistry, São José dos Campos Dental School, São Paulo State University, São Paulo Brazil

\section{Ana Paula Martins Gomes}

Associate Professor, Department of Restorative Dentistry, São José dos Campos Dental School, São Paulo State University, São Paulo Brazil

\section{CORRESPONDING AUTHOR}

CarlosRochaGomes Torres, AssistantProfessor,Department of Restrorative Dentistry, AvenidaEngenheiroFrancisco JoséLongo, 777 Jardim São Dimas São José dos Campos, São Paulo, CEP: 12.245-000, Brazil, Phone:+55(12) 3947 9048, e-mail: carlosrgt@gmail.com 
